\title{
ANÁLISE E APONTAMENTOS EM TORNO DA POLÍTICA DE UM CURRÍCULO MUNICIPAL
}

Ana Lydia Sant Anna Perrone, Marisa da Silva Dias

Universidade Estadual Paulista Júlio - UNESP, Bauru, SP.

\section{RESUMO}

Este trabalho é fruto de reflexões e discussões frente à questão das políticas públicas na Educação abordada na disciplina de Análise de Políticas Públicas no curso de mestrado da Unesp de Presidente Prudente.Este estudo analisou conceitos, características e tipologias das políticas públicas. Neste contexto, apresentamos aqui alguns autores e propomos uma reflexão e análise da formulação e implementação da nova proposta curricular do ensino fundamental da cidade de Bauru. Para realização deste trabalho, a proposta foi de relacionar o objeto de estudo de nossa pesquisa com os conteúdos abordados a partir das leituras, análise de diferentes autores que tratam do ciclo de políticas públicas discussões,e contribuições da disciplina.

Palavras-chave:Política Pública, Currículo Municipal, Ciclo de Política, Ensino Fundamental, Implementação

\section{ANALYSIS AND POINTS AROUND THE POLICY OF A MUNICIPAL CURRICULUM}

\begin{abstract}
This work is the result of reflections and discussions on the issue of public policies in Education addressed in the discipline of Public Policy Analysis in the Unesp course of PresidentePrudente.This study analyzed concepts, characteristics and typologies of public policies. In this context, we present here some authors and propose a reflection and analysis of the formulation and implementation of the new curricular proposal of elementary education of the city of Bauru.Para realization of this work, the proposal was to relate the study object of our research with the contents approached from the readings, analysis of different authors dealing with the cycle of public policy discussions, and contributions of the discipline.
\end{abstract}

Keywords: Public Policy, Municipal Curriculum, Policy Cycle,Elementary School, Implementation 


\section{INTRODUÇÃO}

A proposta deste trabalho foi de analisar a partir da ótica de políticas públicas, a construção, formulação e implementação da proposta curricular para o Ensino Fundamental do município de Bauru/SP.

Este currículo tem como fundamentação teórica a Perspectiva Histórico-Cultural, que compreende "uma perspectiva crítica da produção do conhecimento, posicionando-se contra a fragmentação dos conceitos produzidos historicamente pela humanidade", e propõe como possibilidade de organização de ensino e aprendizagem proposta por Moura (2010) que favoreça o desenvolvimento do conhecimento científico é a Atividade Orientadora de Ensino (AOE), desenvolvida a partir dos pressupostos da teoria histórico-cultural e organizada com a estrutura da atividade proposta por Leontiev.

No caso de um Currículo Municipal podemos aqui optar por uma definição de conjuntos de programas, ações e decisões tomadas pelos governos, enquantoàs políticas públicas são um conjunto de projetos, programas e atividades realizadas pelo governo.

Como uma visão de definição mais ampla, podemos afirmar que a política pública é o Estado em Ação, esta ação é intencional e influencia a vida dos cidadãos que estão nela inseridos.

Neste sentido, podemos também afirmar que não há políticas sem atores, por atores podemos entender que são pessoas que estão atuando diretamente nesta ação, que desenvolvem um papel nela, que interagem e articulam neste processo político. ações.

Estes atores logicamente possuem poderes diferentes e exercerão diferentes formas de

Uma política governamental tem a natureza de um processo, no qual intervêm múltiplos atores, portadores de distintas percepções e dispondo de desiguais recursos de poder, com os quais confrontam-se e organizam (ou não) consensualmente as decisões (DRAIBE, 1991, p. 15).

No caso de um Currículo Municipal de Educação, podemos citar enquanto atores, os professores, diretores, coordenadores, elaboradores do documento, secretário de Educação, dentre outros; além disso, podemos dizer que estes atores influenciam uns aos outros durante o processo político.

Existem várias fases numa política (agenda, formulação, implementação e avaliação) que nos possibilitam analisá-las, em nossas aulas optou-se em seguir a divisão feita por Viana(1996) Agenda, Formulação, Implementação e Avaliação.

Como aqui vamos objetivar o entendimento da formulação da política e o início de sua implementação podemos dizer que os atores podem estar envolvidos nas duas fases aqui elencadas.

Só existe formulação de uma política quando se encontra um problema, e para que ela ocorra faz-se necessário definir um problema público e elaborar uma intervenção para supri-lo. É uma criação de opção para resolvê-lo, e faz-se aí necessário um jogo de negociações.

Esta elaboração segue fases como formulação de alternativas, formulação de políticas e tomada de decisão.

O processo de formulação de políticas para solucionar um problema inscrito na agenda pública permite resolver qual das diferentes alternativas existentes será mais apropriada para diminuir a tensão entre a situação atual e a situação desejada (DIAS; MATOS, 2012, p. 76).

Portanto, no caso de nosso objeto de estudo, Tezani (2013) contextualiza que esta formulação deu-se a partir da ideia inicial para criação do currículo comum e de uma necessidade solicitada ao Departamento Pedagógico pela diretora do Departamento de Ensino Fundamental que enfatizava a elaboração de uma proposta curricular, com conteúdos mínimos para as unidades escolares, proporcionando progressividade dos conteúdos e melhoria da qualidade do 
ensino público municipal. Surge então a ideia de se criar uma proposta curricular mínima, fomentando a permanência e mobilidade do aluno, a melhoria das práticas pedagógicas e o repensar do processo de formação continuada dos professores.

Este processo de formulação pode ser também definido como a busca da solução do problema público envolvido numa política.

A fase da implementação vem logo a seguir da formulação, isto não quer dizer que elas são estanques, mas neste caso podemos visualizar o enfoque de que estas ações são cíclicas, pois elas estão em constante movimento e modificações.

A Lei no 9.394, de 20 de dezembro de 1996, de Diretrizes e Bases da Educação Nacional (LDB), em seu artigo 26, estabelece: Os currículos do ensino fundamental e médio devem ter uma base nacional comum, a ser completada, em cada sistema de ensino e estabelecimento escolar, por uma parte diversificada, exigida pelas características regionais e locais da sociedade, da cultura, da economia e da clientela (BRASIL, 1996). Estabelece também, que compete à União, em colaboração com os Estados, o Distrito Federal e os municípios, estabelecer diretrizes para a educação básica, que nortearão os currículos e seus conteúdos mínimos, de modo a assegurar a formação básica comum. Tais diretrizes comportam uma proposta curricular de âmbito nacional, com força de lei, ainda que permita uma parte diversificada para abrigar as particularidades regionais e locais.

Desta forma, muitos gestores estaduais e municipais têm elaborado seus próprios documentos norteadores para a educação.

Nas redes municipais, a atuação dos gestores educacionais possui certo grau de independência e podem propor políticas próprias para regulação do trabalho pedagógico. Assim, o currículo é um instrumento para direção da prática pedagógica, define o ensino, aborda os fundamentos e conteúdos, sua sequência, dos métodos a serem utilizados, os recursos para aprender e ensinar (por exemplo, livros didáticos e novas tecnologias), avaliação e formação de professores.

Podemos complementar esta definição a partir de Veiga (2002, p.7)

Currículo é uma construção social do conhecimento, pressupondo a sistematização dos meios para que esta construção se efetive; a transmissão dos conhecimentos historicamente produzidos e as formas de assimilá-los, portanto, produção, transmissão e assimilação são processos que compõem uma metodologia de construção coletiva do conhecimento escolar, ou seja, o currículo propriamente dito.

\section{DISCUSSÃO}

A cidade de Bauru preocupou-se a partir de 2009 com a criação de um Departamento Pedagógico inserido ao Departamento de Ensino Fundamental com a elaboração de uma proposta curricular pautada na melhoria da qualidade de ensino público municipal. O objetivo maior desta construção era de obter uma escola de eficiência para a formação de cidadãos plenos.

O projeto contemplou a participação e articulação com a UNESP/Bauru, como uma parceria uma vez que o município não teria como arcar principalmente com a assessoria de profissionais da área para uma edificação do material teórico-metodológico do documento.

Junto a esta articulação, foram convocados docentes ( $1^{\circ}$ ao $5^{\circ}$ ano) de todas as escolas da rede, professores especialistas, coordenadores, diretores para garantir a conformidade com a realidade escolar.

O currículo foi construído paulatinamente, área por área, seguindo o viés do início, com a interação dos professores atuantes na rede ao embasamento teórico fornecido pela universidade.

O currículo municipal de Bauru nasce a partir de trabalhos desenvolvidos por grupos de trabalho do Currículo Comum em sua 1a edição em 2013.

A partir desta publicação, iniciou-se a implementação do Currículo com a supervisão do DPPPE (Departamento de Planejamento, Projetos e Pesquisas Educacionais). 
Em 2016, o material que foi reformulado, foi reeditado. É importante ressaltar que as duas versões foram construídas e elaboradas por um trabalho coletivo e constante dos professores, gestores e do apoio teórico-metodológico da universidade envolvida.

De acordo com a Lei de Diretrizes e Bases da Educação (LDB) (BRASIL, 1996) e o Fundo Nacional de Desenvolvimento do Ensino Fundamental (FUNDEF) (BRASIL, 1996b), foram implantados com a finalidade de distribuir os investimentos governamentais diretamente às escolas de ensino fundamental, principalmente, através de compra e distribuição de livros didáticos e ajuda financeira direta às unidades escolares, o chamado Programa Dinheiro Direto na Escola (PDDE) (BRASIL, 2013).

O currículo escolar vinha sempre acompanhado de uma visão que o apresenta como um documento pronto e estanque, mas atualmente tem-se aplicado a associação por um processo mais participativo, de construção coletiva.

Com esta intenção, a reforma curricular do município de Bauru vem caminhando, construindo e reconstruindo sua trajetória, através de ações conjuntas entre os atores envolvidos em todos os âmbitos, desde funcionários e gestor desta Secretaria de Educação, até seus agentes escolares.

Durante o processo de formulação, todos os professores foram consultados e convidados a participar do processo de elaboração e revisão do currículo comum, em um intenso exercício do fazer democrático. No desenvolvimento deste trabalho, cada área teve autonomia para organizar seus conteúdos buscando articulá-los com os pressupostos teóricos que subsidiam o currículo.

\section{FASES E ABORDAGEM DE UMA IMPLEMENTAÇÃO DE UMA POLÍTICA PÚBLICA:}

Existem várias definições para o que são políticas públicas, Mead (1995) a define como um campo dentro do estudo da política que analisa o governo à luz de grandes questões públicas.

A implementação trata-se de uma fase da política pública que contempla como ela está sendo posta em prática, ou seja, à transformação da política em ação. Podemos também afirmar que nessa fase do ciclo de uma política pública, que se desenrola a resolução do problema de que ela se serve. Esta fase, é onde os atores envolvidos atuam na realização e busca dos objetivos da política pública, neste caso podemos destacar o papel dos diretores das unidades escolares, coordenadores, professores. Nesta fase da política pública, a implementação está totalmente atrelada à interpretação e atuação dos atores que a implementam, pois são eles que decidem a partir do documento a direção onde vão seguir.

Assim, ela é gerada de um esforço coletivo, concretizado paulatinamente pelos atores que ali estão envolvidos.

No caso do Currículo do município de Bauru, esta implementação foi feita de maneira com que os atores participantes desta etapa, pudessem contribuir com ideias e sugestões de modificações constantes, principalmente os atores atuantes especificamente os professores.

Sem implementação, não haveria política pública. A implementação, contudo, vai muito além da simples execução das decisões inicialmente tomadas. Mesmo já tendo havido um processo decisório durante a formulação da política pública, sua implementação não somente enseja execução, como também requer novas decisões. [...] Por isso, é importante ter em mente que as decisões não se encerram durante a formulação - se estendem por todo o período de vigência de uma política pública (RUA, 2013, p. 91).

Este trecho pode corroborar o sentido da implementação no qual estamos destacando neste processo.

Ainda segundo RUA(2013), a implementação não é somente uma execução das decisões, mas sim um ciclo de decisão e ressignificação das mesmas, além disso, este processo deve ser acompanhado por uma reformulação. 
Neste sentido aponta três diferentes abordagens para esta análise: o modelo Top Down(de cima para baixo), o BottonUp (de baixo para cima) e uma mais recente abordagem chamada de Teorias Híbridas.

O modelo Top Down, apresentava um modelo racionalista, determinando que a implementação provém um conjunto pré-determinado , programado e centralizado, onde sempre se origina de uma decisão governamental que define os meios e ações para o alcance do objetivo final. Sendo assim, os principais atores neste processo seriam os burocratas e gestores políticos

O modelo BottomUp, volta suas atenções aos atores de outras instâncias envolvidos nos resultados de das políticas a serem implantadas, acredita que a implementação resulta de atores de todos os níveis do processo, e descentraliza a resolução dos problemas, isto é, tem caráter mais participativo.

E por fim, o modelo advindo das Teorias Híbridas, que concebe a implementação como um processo cíclico, de tentativas e interações, e não determinado o resultado ao fim do processo. Um dos modelos que a teoria nos fornece, é o Modelo Interativo, de Grindle e Thomas (1991).

Neste modelo, a sociedade é agente constante, e há revisão de metas e atuações constantes, a partir de questões que emergem da relação entre os atores da sociedade e os burocratas, que geram movimentos, rejeições e mudanças durante o processo.

Acreditarmos que esta última abordagem vem mais de encontro para a análise desta implementação de política, pois concebe a implementação como resultado aberto, cíclico sem estancar as outras fases da política pública (agenda, formulação, avaliação), já que observamos no decorrer deste trabalho que este movimento reflexivo prevaleceu durante todo este processo, a ainda acontece, já que o currículo tem sido trabalhado e sustentado constantemente principalmente com a formação de professores realizada com eficácia e eficiência.

Como já foi aqui ressaltado os atores envolvidos nesta implementação possuem recursos de poder, haja vista a participação massiva dos professores na elaboração do currículo e nas propostas de mudanças.

No primeiro ano de aplicação do documento nas escolas foi observada grande aceitação e este currículo passa a organizar todo o ensino fundamental do município. Contudo, mesmo sendo aceito e reconhecido ao longo deste trabalho, revelaram-se as primeiras insuficiências e problemas.

Grande parcela da literatura concorda com a ideia de que a implementação é responsável pelo sucesso ou fracasso de uma intervenção governamental na realidade. Os implementadores, se devidamente preparados e motivados, podem mobilizar os recursos necessários para suplantar as dificuldades que venham a surgir ao longo do processo da política pública; entretanto, se despreparados e insatisfeitos, também podem inviabilizar ou sabotar a realização apropriada da política pública, desvirtuando-a(RUA, 2013).

Após a implantação do Currículo Comum em 2013, os coordenadores de área do DPPPE, por meio das supervisões pedagógicas, constataram a necessidade de aprimoramento do documento, pois o mesmo não apresentava a unidade teórica necessária para que o trabalho se desenvolvesse de acordo Teoria Histórico-Cultural.

Em especial no currículo municipal de Bauru, podemos fazer um aporte para essa definição a partir de Saviani (1995, apud BAURU, 2012, p. 35) "o trabalho educativo é uma forma de produção intencional, produzida historicamente e coletivamente pelos homens".

Sabendo da não neutralidade envolvida em um currículo, e visando a formação integral e crítica dos alunos envolvidos na rede, este documento vem amparado pela vertente históricocultural e pela perspectiva democrática e participativa.

Os profissionais envolvidos no sistema municipal de educação de Bauru têm participado com efetividade dos programas de formação continuada, buscando aprofundamento e unidade teórica, visto que a cidade optou numa linha teórica metodológica diferenciada, o que demonstra 
valorização na busca do entendimento da teoria que embasa os pressupostos deste currículo, articulado á prática pedagógica, o que aponta para uma melhoria na qualidade de ensino na rede.

Durante todo esse percurso, podemos colocar que as dúvidas emergem cotidianamente no sentido de que o ciclo permaneça presente, estas dúvidas, emergem da garantia da eficácia ou não desta formação continuada, já que ela é construída constantemente por professores que estavam inseridos no processo de elaboração do currículo.

O documento também afirma que não tem pretensão em "esgotar o assunto com a apresentação formal desse documento, mas sim iniciar um processo constante de revisão curricular no ensino fundamental municipal de Bauru", o que nos reafirma a teoria de que o ciclo da política pública é espiralado e deve permanecer em movimento constante para manter-se vivo e atual.

\section{CONCLUSÃO}

A partir deste trabalho estamos acompanhando todo o processo que permeia a construção, implementação e reformulação deste currículo, que está em movimento constante. Podemos afirmar que os professores, diretores e coordenadores, estão bastante envolvidos e a Secretaria da Educação tem a cada dia investido em cursos de formação tanto teórica, quanto prática para que os resultados deste trabalho seja desencadeador de muitas conquistas para o município.

Quanto aos resultados propriamente ditos, como por exemplo, nas notas em avaliações de larga escala, como somente neste ano letivo este currículo efetivamente foi colocado em prática, não possuímos ainda dados quantitativos para realizar esta análise, porém podemos avaliar que todo esse processo já uma grande conquista no processo de mudança na educação deste município.

\section{REFERÊNCIAS}

BAURU.Currículo Comum para o Ensino Fundamental Municipal. [recurso eletrônico] / Organizadores: Afonso Mancuso de Mesquita, Fernanda Carneiro Bechara Fantin, Flávia Ferreira da Silva Asbhar. - Bauru: Prefeitura Municipal de Bauru, 2012.

.Currículo Comum para o Ensino Fundamental Municipal. [recurso eletrônico] / Organizadores: Afonso Mancuso de Mesquita, Fernanda Carneiro Bechara Fantin, Flávia Ferreira da Silva Asbhar. - Bauru: Prefeitura Municipal de Bauru, 2016.

BRASIL. Lei no 9.394 de 20 de dezembro de 1996. Lei de Diretrizes e Bases da Educação Nacional. Estabelece as diretrizes e bases da educação nacional. Brasília: Câmara dos Deputados, Edições Câmara, 2013.

. Lei no 9424, de 24 de dezembro de 1996. Dispõe sobre o Fundo de Manutenção e Desenvolvimento do Ensino Fundamental e de Valorização do Magistério. Disponível em: $<$ www.senado.gov.br

. Ministério da Educação. Resolução/CD/FNDE no 10, de 18 de abril de 2013. Dispõe sobre os critérios de repasse e execução do Programa Dinheiro Direto na Escola (PDDE), em cumprimento ao disposto na Lei 11.947, de 16 de junho de 2009. Diário Oficial da União, Brasília, $19 \mathrm{abr} .2013$.

GRINDLE, Merilee S. e THOMAS, John W. Public choices and policy change: The political economy of reform in developing countries. London: The Jonhs Hopkins University Press, 1991. 
MEAD, L. M.Public Policy: Vision, Potential, Limits.PolicyCurrents, Fevereiro: 1-4. 1995.

MOURA, M.O.; et.al. A atividade orientadora de ensino como unidade entre ensino e aprendizagem. In: MOURA, M.O. (Coord.). A atividade pedagógica na teoria histórico-cultural. Brasília, DF: Líber Livro, 2010.

VEIGA NETO, A. De Geometrias, Currículo e Diferenças. IN: Educação e Sociedade, Dossiê Diferenças-2002.

VIANA, A. L. Abordagens metodológicas em políticas públicas. Revista de Administração Pública, Rio de Janeiro, v. 30, n. 2, p. 5-43, 1996.

RUA, M.G.Para aprender políticas públicas. Brasília, DF: IGEPP, 2013.

TEZANI, T. C. R. A estrutura do currículo comum para o ensino fundamental municipal. In:

(Org.) Currículo comum para o ensino fundamental municipal de Bauru. Bauru: Faculdade de Ciências/UNESP, 2013. 